Original Research Paper

\title{
Length Measurement of Long Gauge Blocks by Interferometer
}

\author{
${ }^{1}$ Kanokporn Kohmun, ${ }^{1}$ Pichet Limsuwan, ${ }^{2}$ Monludee Ranusawud and ${ }^{1}$ Prathan Buranasiri \\ ${ }^{l}$ Department of Physics, King Mongkut's Institute of Technology Ladkrabang, Bangkok, Thailand \\ ${ }^{2}$ National Institute of Metrology (Thailand), Klong Luang, Pathumthani 12120, Thailand
}

\author{
Article history \\ Received: 03-07-2020 \\ Revised: 18-09-2020 \\ Accepted: 19-09-2020 \\ Corresponding Author: \\ Kanokporn Kohmun \\ Department of Physics, King \\ Mongkut's Institute of \\ Technology Ladkrabang, \\ Bangkok, Thailand \\ Email: 57605011@kmitl.ac.th
}

\begin{abstract}
A gauge block interferometer with a vacuum chamber was designed and constructed for the measurement of gauge block lengths between 10 to $1,000 \mathrm{~mm}$. In the chamber, four gauge blocks under the length measurement can be mounted on the measuring table. Furthermore, the length of all four gauge blocks can be measured continuously in one measurement. In this study, four gauge blocks with the nominal length of $125,200,400$ and $500 \mathrm{~mm}$ were used for the length measurement. The environment parameters in the vacuum chamber including temperature, pressure, relative humidity and $\mathrm{CO}_{2}$ concentration were measured. The refractive index of air which depends on environment parameters was determined by using updated Edlén equation. Then, the lengths of four gauge blocks were measured and found to be 125.00025, 200.00019, 400.00070 and 500.00064, respectively.
\end{abstract}

Keywords: Long Gauge Block, Interferometer, Refractive Index of Air, Edlén Equation, Length Measurement

\section{Introduction}

Gauge blocks are generally used for accurate calibration of length measuring instruments that are widely used in industries. To improve accuracy of length measurements, it requires more accurately calibrated gauge blocks as the references. Especially, there is a growing demand for accurate calibrations of gauge blocks longer than $200 \mathrm{~mm}$.

The length measurement of gauge blocks is generally carried out by two methods: (1) The comparison measurement and (2) the absolute measurement. Interferometry, an absolute measurement method, is used for the length measurement of high-grade gauge blocks (grade K) as recommended in ISO 3650:1998 (British Standard, 1998). Even though a very high accuracy measuring methods using an interferometer, there are critical errors in interferometry caused by the environment parameters such as temperature, pressure, relative humidity and $\mathrm{CO}_{2}$ concentration (Birch et al., 1993; JongHan et al., 2007; Andrew et al., 2010; Diz-Bugarin et al., 2013). Since the refractive index of air surrounding the interferometer depends on these parameters, therefore, the wavelength of the laser used for the length measurement of gauge blocks also depends on these parameters.

The gauge block interferometer systems were developed by various National Metrology Institute (NMI) to measure the length of gauge blocks (Hamid et al., 2005; Darnedde 1992; Lewis 1994; Decker and Pekelsky, 1997). In addition, the interferometers for the length measurement of long gauge blocks up to $1000 \mathrm{~mm}$ were developed by various researchers Haitjema and Kotteb (1998) developed an interferometer for the calibration of long gauge blocks in the 100-1,000 mm range. Bitou et al. (2001) developed an interferometer using an optical multimode fiber for measuring the gauge blocks of up to 1,000 mm long. Decker et al. (2003a) developed an interferometer based on Kösters interferometer for measuring the gauge blocks of $1 \mathrm{~m}$ long. Decker et al. (2003b) developed the multiple-wavelength interferometer for long gauge block calibration. Wengierow et al. (2008) developed the multiple-wavelength interferometer based on Twyman-Green interferometer with automatic data analysis based on phase fraction method and later the automatic fringe pattern analysis method was modified. Wengierow et al. (2013) further developed the above automatic multiple-wavelength interferometer system with extended measurement range for calibration of long gauge block up to $1 \mathrm{~m}$.

The National Institute of Metrology of Thailand (NIMT) was established in 1997 as a public agency under the supervision of Ministry of Science and Technology. The mission is to develop the national 
measurement standards to be recognized internationally and to disseminate the measuring accuracy to Thai community. The main works of NIMT are the calibration services. The NIMT provides the calibration services to the calibration laboratories and industrial sectors in order that their measuring equipments are traceable to the national and international standards. The calibration services provided are related to 5 metrology departments including chemical metrology and biometry, dimensional metrology, electrical metrology, mechanical metrology and thermometry and optical metrology departments; and acoustics and vibration group.

At present, only one commercial gauge block interferometer system available at NIMT is the frequencystabilized He-Ne laser at 633 and $543 \mathrm{~nm}$ with a measuring uncertainty of $0.025 \mu \mathrm{m} \pm 0.2 \times 10^{-6} \mathrm{~L}$ ( $\mathrm{L}=$ gauge block length, $\mathrm{mm}$ ) at an operating temperature of $20 \pm 0.5^{\circ} \mathrm{C}$. This gauge block interferometer system is the automatic primary-level measuring instrument for gauge block lengths between 10 to $250 \mathrm{~mm}$ using optical interference which based on Twyman-Green interferometer.

In this study, a gauge block interferometer with a vacuum chamber was designed and constructed for the length measurement of gauge block with a long length and wider range of the length between 10 to $1,000 \mathrm{~mm}$.

Furthermore, four gauge blocks can be mounted on the measuring table and the length of all four gauge blocks can be measured in one measurement.

\section{Gauge Block Interferometer Chamber}

Gauge block interferometer chamber was designed and constructed for a long gauge block measurement using interferometer as shown by a schematic diagram in Fig. 1.
The system was modified from the gauge block interferometer developed and described in previous work (Ranusawud et al., 2013). In that system, when the length measurement of the first gauge block was finished, the top cover of the chamber must be opened for adjusting the next gauge block to be measured in the path of mirror $\mathrm{M}_{2}$. Prior to the length measurement, the air inside the chamber must be evacuated and it takes time. Therefore, four gauge blocks cannot be measured continuously.

The new system was designed for measuring four long gauge blocks continuously in one measurement.

The details on mechanical design for vacuum insulating wall have been described elsewhere (Ranusawud et al., 2014). The chamber was vacuum insulating wall with a dimension of $(\mathrm{W} \times \mathrm{L} \times \mathrm{H}) 1.2 \times 2 \times 0.5 \mathrm{~m}$. The vacuum insulating wall of gauge block chamber was constructed to reduce the thermal conductivity in system and to obtain high stability of temperature. The mechanical design of vacuum insulating wall is mainly composed of outer and inner aluminum plates with a thickness of 8 and $10 \mathrm{~mm}$, respectively. The five vacuum insulating walls (four side plates and one top plate) were connected together by vacuum rubber tube. To prevent the collapse of two large aluminum plates, the Polyethylene (PE) frames were inserted between them. The gap between two aluminum plates was evacuated to have a pressure of $0.9 \mathrm{~m}$ bar by a rotary pump (Edwards: RV12). The refrigerated and heating circulator (Julabo, model: F34-HL) was used to control the temperature of water in the chamber with a resolution of $0.01^{\circ} \mathrm{C}$ in the temperature range of 10 to $70^{\circ} \mathrm{C}$. The water was circulated in gauge block chamber through the stainless steel pipe for stabilizing temperature in the chamber. The water at a flow rate of 20 to $261 /$ min was passed through the pipe.

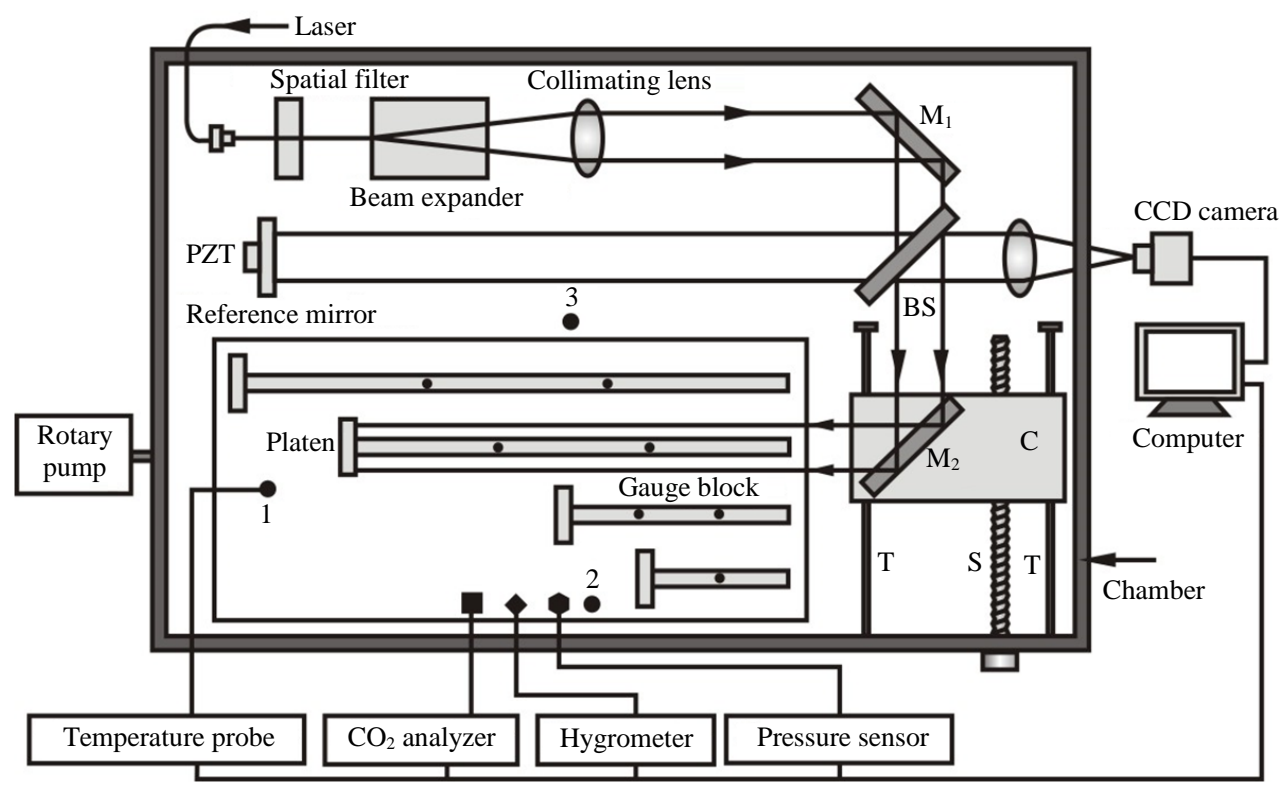

Fig. 1: Schematic diagram of gauge block interferometer chamber 
The environment parameters including temperature, pressure, relative humidity and $\mathrm{CO}_{2}$ concentration inside the chamber were measured at various positions as shown in Fig. 1. The temperature was measured at three positions using platinum resistance temperature probes (Netsushin, Plamic Pt100) and display on a thermometer readout (Fluke, 1590). The air pressure was measured by a pressure transducer (DHI Instruments, RPM4). The relative humidity in the chamber was measured using a hygrometer transmitter (Vaisala, HMT333). The $\mathrm{CO}_{2}$ concentration was measured using a gas filter correlation carbon dioxide analyzer (Teledyne Instrument, 360EM).

It is worth to point out that in our previous work (Ranusawud et al., 2013), the temperature was measured at 5 positions in the chamber. However, in this study the temperature was measured at 3 positions in the chamber.

\section{Interferometer System}

The interferometer system was installed in the aluminum chamber as shown in Fig. 1. All the optical components were mounted on $1 \times 1.8 \mathrm{~m}$ breadboard. The configuration of interferometer was based on TwymanGreen interferometer. Iodine stabilized He-Ne laser was used as the light source. The laser beam with a wavelength of $633 \mathrm{~nm}$ was passed into the chamber and passed through a spatial filter to clean up the laser beam. It was expanded by a beam expander and collimated by a collimating lens to obtain parallel beam with a diameter of $50 \mathrm{~mm}$. The laser beam was reflected at the mirror $\mathrm{M}_{1}$ and passed to the nonpolarizing beam splitter BS. Then, the laser beam was separated into two beams of nearly the same intensity. The first beam passed to the reference mirror with a flatness of $\lambda / 20$ that mounted on the Piezo-electric Transducer (PZT). The second beam passed to the mirror $\mathrm{M}_{2}$ and reflected to the gauge block under the length measurement that wrung on the platen. The beams reflected from the surfaces of the platen and gauge block, then, interfered with the beam reflected from reference mirror surface. The interference fringes were captured by a CCD camera. Interference in this setup can be explained by assuming that an image of reference mirror is formed at $\mathrm{R}^{\prime}$ by the beam splitter as shown in Fig. 2 (Doiron and Beers, 1995).

It is noted that the mirror $\mathrm{M}_{2}$ mounted on a carriage $\mathrm{C}$ can be moved along linear tracks $\mathrm{T}$ by a screw $\mathrm{S}$. The mirror $\mathrm{M}_{2}$ can be moved to the position corresponding with the gauge block under the length measurement. Therefore, for each length measurement experiment, all four gauge blocks can be measured continuously in one hour.

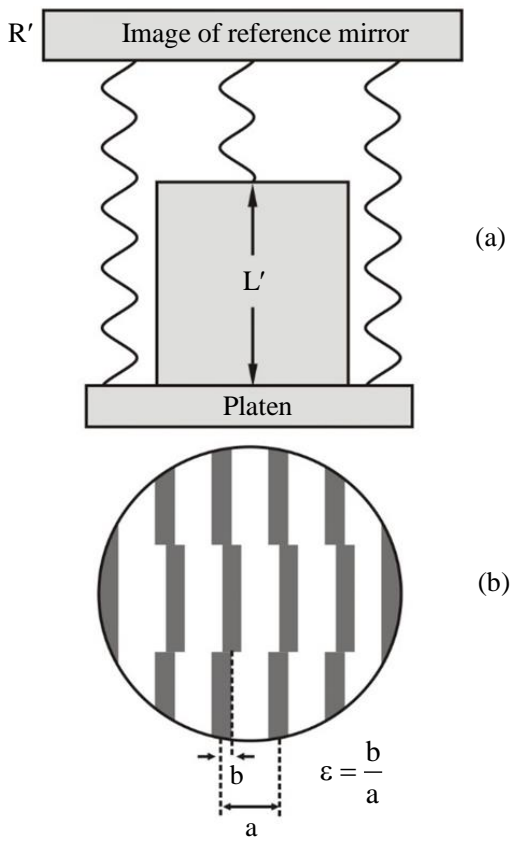

Fig. 2: (a) Depiction of the incidence light to the top of the gauge block and the top surface of platen and (b) observed interference fringes

The optical path difference between the beam reflected from reference mirror surface to platen surface and the beam reflected from reference mirror surface to gauge block surface is $2 L^{\prime}$, where $L^{\prime}$ is the nominal length of gauge block. The measured length of gauge block (L) will be equal to a whole number of half wavelengths $(N)$, plus the fraction $b / a$ of the half wavelength of the light in which the fringes are observed (Galyer and Shotbolt, 1990):

$$
\begin{aligned}
L & =N \frac{\lambda_{\text {air }}}{2}+\frac{b}{a} \frac{\lambda_{\text {air }}}{2} \\
L & =\left(N+\frac{b}{a}\right) \frac{\lambda_{\text {air }}}{2} \\
L & =(N+\varepsilon) \frac{\lambda_{\text {air }}}{2}
\end{aligned}
$$

where, $\varepsilon=b / a$ is the fringe fraction, $a$ is the distance between the dark fringes on the platen and $b$ is the distance between the dark fringes on the platen and the dark fringes on gauge block.

\section{Determination of Gauge Block Length by Interferometer (Doiron and Beers, 1995)}

To determine the length of gauge block by interferometer, the calculating process is done in 3 steps: (1) Calculation of the wavelength at observed ambient conditions, (2) calculation of the whole number of 
fringes in the gauge block length from its predicted length and the laser wavelength in ambient air and (3) calculation of the gauge block length from the whole number of fringes, the observed fringe fraction, wavelength in ambient air, gauge block temperature and interferometric correction factors.

\section{Calculation of the Wavelength}

The laser wavelength is assumed to be constant in vacuum and denoted by $\lambda_{v}$. However, in the air the laser wavelength is changed from $\lambda_{v}$ to the ambient wavelength $\left(\lambda_{\text {air }}\right)$ due to the refractive index of air. The laser wavelength in vacuum $\left(\lambda_{v}\right)$, the laser wavelength in air $\left(\lambda_{\text {air }}\right)$ and the refractive index of air $\left(n_{\text {air }}\right)$ are related by equation:

$$
\lambda_{\text {air }}=\frac{\lambda_{v}}{n_{\text {air }}}
$$

where, $\lambda_{\text {air }}=\lambda_{x t p R}$ is the laser wavelength in air at the time of measurement in the interferometer chamber, i.e., temperature $(t)$, pressure $(p)$, relative humidity $(R)$ and $\mathrm{CO}_{2}$ content $(x)$ and $n_{\text {air }}=n_{x t p R}$ is the refractive index of air at the time of measurement.

\section{Calculation of the Whole Number of Fringes}

The method to determine the whole number of fringes is valid if the gauge block length is known to be better than 0.5 fringe ( 1 fringe is $\lambda / 2$ ) from its history or from an independent measured process. The calculation is as follows:

$N=\frac{2 L^{\prime}\left[1+\alpha\left(t^{\prime}-20\right)\right]}{\lambda_{\text {air }}}$

Where:

$N=$ The number of interference fringes in the length of gauge block

$L^{\prime} \quad=$ The nominal length of gauge block taken from its history or and independent measurement

$\lambda_{\text {air }}=$ The wavelength at the time of measurement

$t^{\prime}=$ The gauge block temperature at the time of measurement

\section{Determination of the Air Refractive Index}

In our previous work (Ranusawud et al., 2013), the updated Edlén equation (Birch and Downs, 1993; 1994), was used to calculate refractive index of air in a long gauge block interferometer developed at National Institute of Metrology (Thailand) by assuming that $\mathrm{CO}_{2}$ content $(x)$ is constant at $450 \mathrm{ppm}$. The refractive index of air in a long gauge block interferometer at any temperature $(t)$, pressure $(p)$ and relative humidity $(R)$ is expressed by:

$$
\begin{aligned}
& n_{\text {air }}=n_{t p R} \\
& =1+\left(8342.54+\frac{2406147}{130-\lambda_{v}^{-2}}+\frac{15998}{38.9-\lambda_{v}^{-2}}\right) \\
& \left(\frac{p}{96095.43}\right)\left[\frac{1+10^{-8}(0.601-0.00972 t) p}{1+0.003661 \mathrm{t}}\right] \times 10^{-8} \\
& -R\left(8.753+0.036588 t^{2}\right)\left(0.037345-0.000401 \lambda_{v}^{-2}\right) \times 10^{-8}
\end{aligned}
$$

In our recent work (Kohmun et al., 2020), the $\mathrm{CO}_{2}$ content $(x)$ was also considered as a variable parameter and it was taken into account. Therefore, the equation used for the calculation of refractive index of air is given by:

$$
\begin{aligned}
& n_{\text {air }}=n_{x t p R} \\
& =1+[1+0.54(x-0.0003)] \\
& \left(8342.54+\frac{2406147}{130-\lambda_{v}^{-2}}+\frac{15998}{38.9-\lambda_{v}^{-2}}\right)\left(\frac{p}{96095.43}\right) \\
& \times\left[\frac{1+10^{-8}(0.601-0.00972 \mathrm{t}) p}{1+0.003661 t}\right] \times 10^{-8} \\
& -R\left(8.753+0.036588 \mathrm{t}^{2}\right)\left(0.037345-0.000401-\lambda_{v}^{-2}\right) \times 10^{-8}
\end{aligned}
$$

\section{Measurement of Environment Parameters in Gauge Block Interferometer Chamber}

Prior to the measurement of environment parameters in gauge block interferometer chamber, the chamber must be placed in a room with a controlled temperature and relative humidity of $20 \pm 0.5^{\circ} \mathrm{C}$ and $50 \pm 10 \%$, respectively. The temperature, pressure, relative humidity and $\mathrm{CO}_{2}$ concentration were measured continuously for $12 \mathrm{~h}$. However, these parameter values at the 6th $h$ were used for the calculation of refractive index of air in the long gauge block interferometer chamber. We used the parameter values at the 6 th $\mathrm{h}$ because it is average hour between $0-12 \mathrm{~h}$ and hence all the parameter values are closed to average values.

\section{Length Measurement of the Gauge Blocks}

Four gauge blocks with the nominal length of 125 , 200, 400 and $500 \mathrm{~mm}$ with a certificate number S10G00263 manufactured by Mitutoyo, Japan were used for the length measurement.

Since our gauge block interferometer developed in this study can be used to measure the length of four gauge blocks in one experiment by moving $\mathrm{M}_{2}$ to the position of each gauge block to be measured, therefore, the interference fringes obtained from all four gauge blocks can be done within one hour. 


\section{Results and Discussion}

In this study, the light source was an iodine stabilized He-Ne laser with a wavelength of $633 \mathrm{~nm}$. The laser wavelength in vacuum $\left(\lambda_{v}\right)$ is $632.990677981 \mathrm{~nm}$.

Figure 3 shows the variation of temperature, pressure, relative humidity and $\mathrm{CO}_{2}$ concentration as a function of time in 12 h. From Fig. 3, it was found that from $0^{\text {th }}$ to 12th the temperature, pressure, relative humidity and $\mathrm{CO}_{2}$ concentration were varied from 19.943 to $19.963^{\circ} \mathrm{C}$, 99999 to $100378 \mathrm{~Pa}, 51.9$ to $52.4 \%$ and 406.0 to 456.0 ppm, respectively. That is, the range of variation are $0.020^{\circ} \mathrm{C}, 379 \mathrm{~Pa}, 0.5 \%$ and $50 \mathrm{ppm}$ with an average values (dot lines) of $19.950^{\circ} \mathrm{C}, 100174 \mathrm{~Pa}, 52.2 \%$ and $437.0 \mathrm{ppm}$. However, at the 6 th $\mathrm{h}$ the temperature, pressure, relative humidity and $\mathrm{CO}_{2}$ concentration were found to be $19.950^{\circ} \mathrm{C}, 100213 \mathrm{~Pa}, 52.3 \%$ and $454.6 \mathrm{ppm}$, respectively. It is seen that all the parameters at the 6 th $\mathrm{h}$ are nearly equal to those of average parameter values.
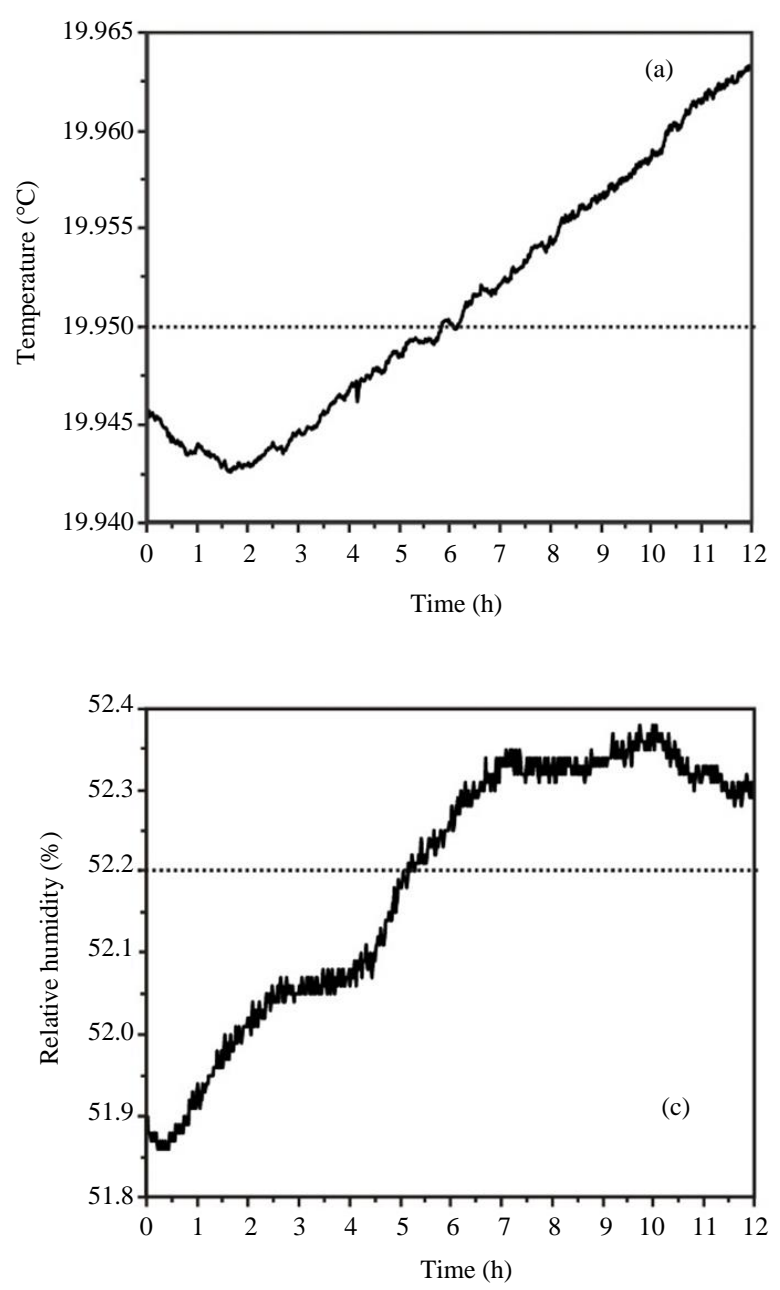

Then, these environment parameter values at the 6 th $\mathrm{h}$ were used for the calculation of $n_{\text {air }}$.

The $125 \mathrm{~mm}$ - long gauge block was the first one that was set for the length measurement. Figure 4 shows the fringe patterns obtained from $125 \mathrm{~mm}$ - long gauge block with the image size of $525 \times 451$ pixels. The fringe fraction $(\varepsilon)$ was then determined from the fringe patterns.

The refractive index of air $\left(n_{\text {air }}\right)$ at the time of measurement, i.e., at the 6 th $\mathrm{h}$ was calculated using Equation (5) and the obtained result was:

$$
n_{\text {air }}=1.000268440
$$

Then, the laser wavelength in air was determined using Equation (2) and the obtained result was:

$$
\lambda_{\text {air }}=\frac{\lambda_{v}}{n_{\text {air }}}=632.820803564
$$
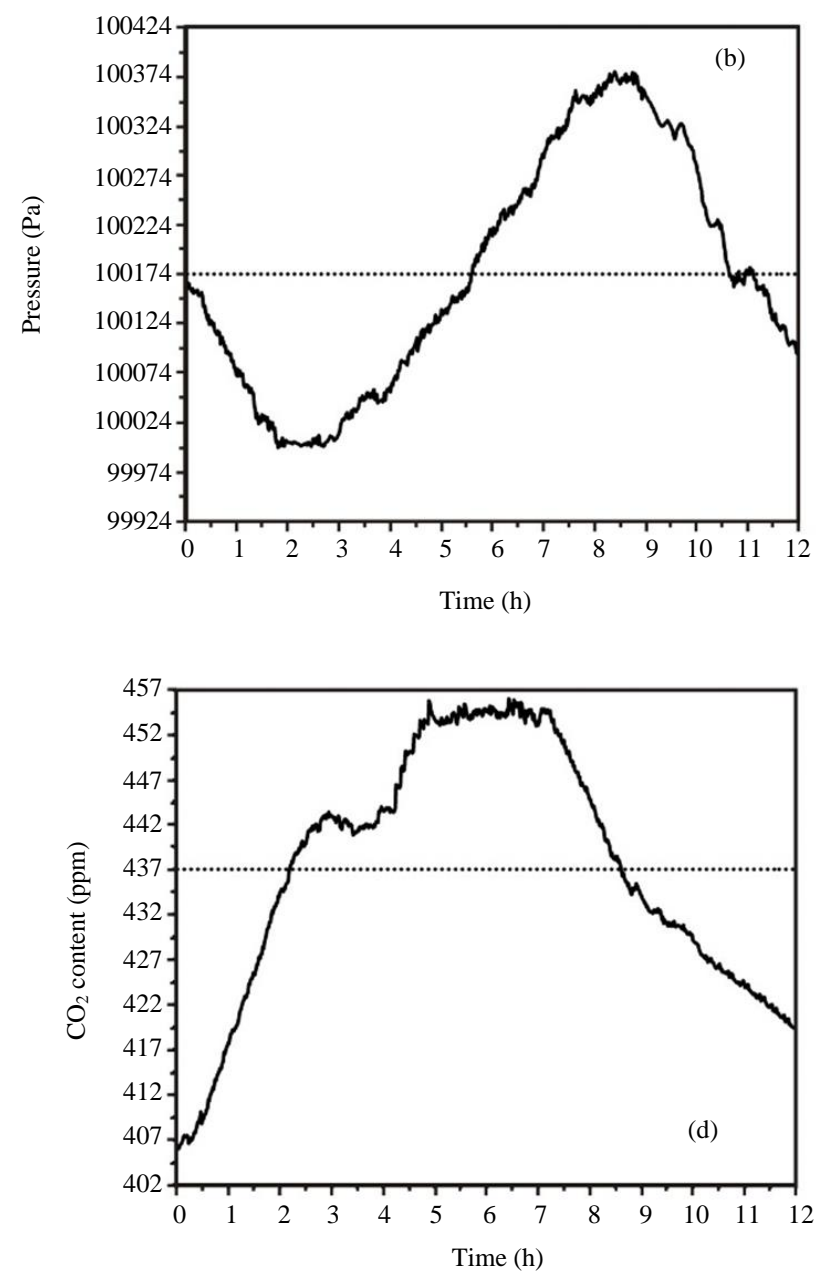

Fig. 3: Variation of the environment parameters in the long gauge block chamber with time as measured for $12 \mathrm{~h}$ 


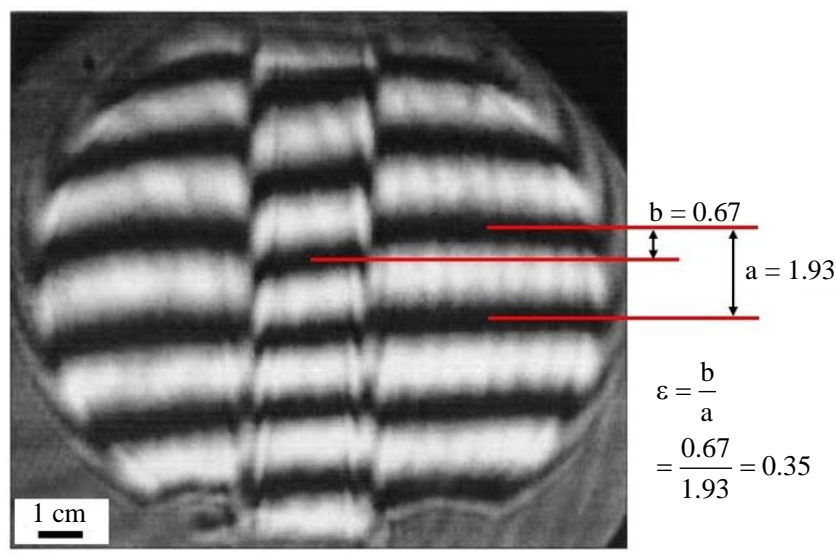

Fig. 4: Typical fringe patterns with the values of $\mathbf{a}$ and $\mathbf{b}$ for $125 \mathrm{~nm}$-long gauge block

Table 1: Whole number of fringes $(N)$, fringe fraction $(\varepsilon)$ and measured length for four gauge blocks

\begin{tabular}{llllll}
\hline $\begin{array}{l}\text { Nominal length } \\
\left(L^{\prime}\right)(\mathrm{mm})\end{array}$ & $\begin{array}{l}\text { Whole number } \\
\text { of fringes }(N)\end{array}$ & $\begin{array}{l}\text { Fringe fraction } \\
(\varepsilon)\end{array}$ & $\begin{array}{l}\text { Certificate length } \\
\pm \text { Uncertainty }(\mathrm{mm})\end{array}$ & $\begin{array}{l}\text { Measured length }(\mathrm{mm}) \\
n_{\text {air }} \text { Equation }(5)\end{array}$ & $n_{\text {air }}$ Equation $(4)$ \\
\hline 125 & 395057 & 0.35 & $125.00011 \pm 0.00005$ & 125.00025 & 125.00026 \\
200 & 632091 & 0.08 & $200.00016 \pm 0.00007$ & 200.00019 & 200.00020 \\
400 & 1264183 & 0.15 & $400.00044 \pm 0.00012$ & 400.00070 & 400.00071 \\
500 & 1580228 & 0.19 & $500.00005 \pm 0.00015$ & 500.00064 & 500.00065 \\
\hline
\end{tabular}

The whole number of fringes $(N)$ was determined using Equation (3). Where, the linear thermal expansion coefficient $(\alpha)$ of gauge black was $10.8 \times 10^{-6}{ }^{\circ} \mathrm{C}^{-1}$ and the gauge block temperature at the time of measurement $\left(t^{\prime}\right)$ was $20.165^{\circ} \mathrm{C}$. Finally, the $125 \mathrm{~mm}$ - long gauge block was determined using Equation (1) and the measured length was found to be $125.00025 \mathrm{~mm}$. The length measurements were carried out for 125, 200, 400 and $500 \mathrm{~mm}$ - long gauge blocks. The fringe patterns for 125, 200, 400 and $500 \mathrm{~mm}$ - long gauge blocks were recorded and the values of $N, \varepsilon$ and length $(L)$ were determined. For the measured lengths of the gauge blocks, the air refractive index $\left(n_{\text {air }}\right)$ was calculated from Equation (5). However, we also calculated $n_{\text {air }}$ from Equation (4) and the measured lengths were obtained. The measured lengths using Equation (5) and (4) and the certificate length as calculated from Mitutoyo's certificate number S10G00263 are given in Table 1. Table 1 shows the values of $N, \varepsilon, L$ and certificate length with uncertainty values for all four gauge blocks.

It is seen from Table 1 that the measured length values obtained from Equation (5) give a higher accuracy than those of Equation (4). That is the $\mathrm{CO}_{2}$ concentration has effect on the length measurement of the long gauge blocks in the interferometer.

Uncertainty of measured gauge blocks length was the uncertainty of the interference fringe number. Therefore, the gauge block length is determined by the uncertainty of a half wavelength in Equation (2), which is $0.00032 \mathrm{~mm}$. It means that: (1) The length of $125 \mathrm{~mm}$ gauge block could be not only $125.00025 \mathrm{~mm}$ with deviation from nominal value of $+0.00025 \mathrm{~mm}$, but also $124.99993 \mathrm{~mm}$ with deviation $0.00007 \mathrm{~mm}$, (2) the length of $200 \mathrm{~mm}$ gauge block could be not only $200.00019 \mathrm{~mm}$ with deviation from nominal value of $+0.00019 \mathrm{~mm}$, but also $199.99987 \mathrm{~mm}$ with deviation $-0.00013 \mathrm{~mm}$, (3) the length of $400 \mathrm{~mm}$ gauge block could be not only $400.00070 \mathrm{~mm}$ with deviation from nominal value of $+0.00070 \mathrm{~mm}$, but also $400.00038 \mathrm{~mm}$ with deviation $+0.00038 \mathrm{~mm}$ or $400.00006 \mathrm{~mm}$ with deviation +0.00006 and (4) the length of $500 \mathrm{~mm}$ gauge block could be not only $500.00064 \mathrm{~mm}$ with deviation from nominal value of $+0.00064 \mathrm{~mm}$, but also $500.00032 \mathrm{~mm}$ with deviation $+0.00032 \mathrm{~mm}$ or $500.00000 \mathrm{~mm}$ with deviation +0.00000 . All the measured length values obtained from Equation (5) are closer to the nominal length, particularly the obtained length values of $400 \mathrm{~mm}$ and 500 mm gauge blocks are closer not only to the nominal lengths, but also to the certificate length values.

\section{Conclusion}

The interferometer system installed in aluminium chamber for the length measurement of long gauge blocks was designed and constructed. The wall of the chamber was the vacuum insulating wall to reduce the thermal conductivity in system and to obtain high stability of temperature. The high interferometer system could be used to measure the length of four gauge blocks at the same time. The length measurements were carried out on four gauge blocks with the nominal length of 125 , 
200, 400 and $500 \mathrm{~mm}$. Two equations, i.e., Equation (4) and (5), relating to environment parameters were used for the calculation of air refractive index. The measured lengths were, then, compared with the certificate values.

\section{Acknowledgement}

Kanokporn Kohmun would like to thank Dr. Monludee Ranusawud and National Institute of Metrology of Thailand (NIMT) for providing all facilities to make this work complete.

\section{Funding}

This work was financially supported by Department of Physics, King Mongkut's Institute of Technology Ladkrabang.

\section{Authors Contributions}

Kanokporn Kohmun: Setup and carried out the experiment, collected all the measurement data and prepared the original manuscript.

Pichet Limsuwan: Helped in writing and approved the manuscript.

Monludee Ranusawud: Provided all the equipments used in the experimental setup.

Prathan Buranasiri: Read and approved the manuscript.

\section{Compliance with Ethical Standards}

This article is original and contains unpublished material. It is confirmed that all of the authors have read and approved the manuscript and there are no ethical issues involved.

\section{Ethical Approval}

This article does not contain any work with human participants or animals.

\section{References}

Andrew, J. L., Hughes, B., \& Aldred, P. J. (2010). Longterm study of gauge block interferometer performance and gauge block stability. Metrologia, 47(4), 473.

Birch, K. P., \& Downs, M. J. (1993). An updated Edlén equation for the refractive index of air. Metrologia, 30(3), 155.

Birch, K. P., \& Downs, M. J. (1994). Correction to the updated Edlén equation for the refractive index of air. Metrologia, 31(4), 315.

Birch, K. P., Reinboth, F., Ward, R. E., \& Wilkening, G. (1993). The effect of variations in the refractive index of industrial air upon the uncertainty of precision length measurement. Metrologia, 30(1), 7.
Bitou, Y., Hirai, A., Yoshimori, H., Hong, F. L., Zhang, Y., Onae, A., \& Seta, K. (2001, October). Gauge block interferometer using three frequency-stabilized lasers. In Recent Developments in Traceable Dimensional Measurements (Vol. 4401, pp. 288297). International Society for Optics and Photonics.

British Standard, 1998. International Organization for Standardization (ISO), Geometrical Product Specifications (GPS)-Length standards-Gauge blocks (ISO 3650:1998). http://www.isothai.com/forums/index.php?app=core $\&$ module $=$ attach $\&$ section $=$ attach \&attach_id=6126

Darnedde, H. (1992). High-precision calibration of long gauge blocks using the vacuum wavelength comparator. Metrologia, 29(5), 349.

Decker, J. E., \& Pekelsky, J. R. (1997). Gauge block calibration by optical interferometry at the national research council Canada. in presented at the Measurement Science Conference NRC Internal Report No.40002.

Decker, J. E., Miles, J. R., Madej, A. A., Siemsen, R. F., Siemsen, K. J., de Bonth, S., ... \& Pekelsky, J. R. (2003a). Increasing the range of unambiguity in step-height measurement with multiplewavelength interferometry-application to absolute long gauge block measurement. Applied optics, 42(28), 5670-5678.

Decker, J. E., Schodel, R., \& Bonsch, G. (2003b, November). Next-generation Kösters interferometer. In Recent Developments in Traceable Dimensional Measurements II (Vol. 5190, pp. 14-23). International Society for Optics and Photonics.

Diz-Bugarin, J., Dorrio, B. V., Blanco, J., Miranda, M., Outumuro, I., \& Valencia, J. L. (2013). Design of an interferometric system for gauge block calibration. Optical Engineering, 52(4), 045601.

Doiron, T., \& Beers, J. S. (1995). The Gage Block Handbook. US Department of Commerce, Technology Administration, National Institute of Standards and Technology.

Galyer, J. F. W., \& Shotbolt, C. R. (1990). Metrology for engineers. Cassell Pub. Ltd, 1990. https://kupdf.net/download/galyer-j-f-w-shotbolt-cr-metrology-for-engineers-fifthedition_590357bcdc0d60ca1e959ef8_pdf

Haitjema, H., \& Kotte, G. J. (1998, September). Long gauge block measurements based on a TwymanGreen interferometer and three stabilized lasers. In Recent Developments in Optical Gauge Block Metrology (Vol. 3477, pp. 25-34). International Society for Optics and Photonics.

Hamid, R., Sendogdu, D., \& Erdogan, C. (2005). The temperature stabilization and temperature measurement of a Kösters interferometer. Measurement Science and Technology, 16(11), 2201. 
Jong-Han, J., Kim, Y. J., Kim, Y., \& Kim, S. W. (2007). Absolute distance measurements using the optical comb of a femtosecond pulse laser. Int. J. Precis. Eng. Manuf, 8(4), 22-26.

Kohmun, K., Limsuwan, P., Ranusawud, M., \& Buranasiri, P. (2020). Effect of the carbon dioxide concentration on the Refractive Index of air in a long gauge block interferometer. Instrumentation Science \& Technology, 48(4), 350-360.

Lewis, A. (1994). Measurement of length, surface form and thermal expansion coefficient of length bars up to $1.5 \mathrm{~m}$ using multiple-wavelength phase-stepping interferometry. Measurement Science and Technology, 5(6), 694.

Ranusawud, M., Limsuwan, P., Somthong, T., \& Vacharanukul, K. (2013). Effects of the environment on refractive index of air in long gauge block interferometer. Precision Engineering, 37(3), 782-786.

Ranusawud, M., Limsuwan, P., Vatcharanukul, K., \& Somthong, T. (2014). High stability of temperature control using vacuum insulated wall for gauge block measurement. In Key Engineering Materials (Vol. 613, pp. 133-138). Trans Tech Publications Ltd.
Wengierow, M., Sałbut, L., \& Ramotowski, Z. (2011, May). Interferometric multiwavelength system for long gauge blocks measurements. In Optical Measurement Systems for Industrial Inspection VII (Vol. 8082, p. 80822R). International Society for Optics and Photonics.

Wengierow, M., Salbut, L., Pakula, A., \& Lukaszewski, D. (2008, August). Multi-wavelength interferometer for high accuracy measurement of long gauge blocks. In Interferometry XIV: Applications (Vol. 7064, p. 70640N). International Society for Optics and Photonics.

Wengierow, M., Salbut, L., Ramotowski, Z., Szumski, R., \& Szykiedans, K. (2013). Measurement system based on multi-wavelength interferometry for long gauge block calibration. Metrology and Measurement Systems, 20(3). 